\title{
Community acquired, nursing home acquired and hospital acquired pneumonia: A five-year review of the clinical, bacteriological and radiological characteristics
}

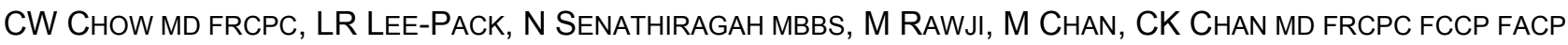

CW Chow, LR Lee-Pack, N Senathiragah, M Rawji, M Chan, CK Chan. Community acquired, nursing home acquired and hospital acquired pneumonia: A five-year review of the clinical, bacteriological and radiological characteristics. Can J Infect Dis 1995;6(6):317-325.

PuRPose: To assess the contemporary clinical, bacteriological and radiographic features of hospitalized patients with community acquired (CA), nursing home acquired (NA) and hospital acquired pneumonia (HA) and to examine patient outcome.

Patients And Methods: All hospital records of patients with pneumonia over a five-year period from April 1987 to March 1992 were reviewed retrospectively. Patients included in the study were all those with a diagnosis of pneumonia as identified by computer records of diagnostic codes at discharge; patients with a specific diagnosis of Pneumocystis carinii pneumonia were excluded. Of 74,435 discharges over the five-year period, 1782 patients met the inclusion criteria. RESULTS: Charts of 1622 of the total 1782 cases were reviewed. Mean age was 64.4 years with $59.4 \%$ men and $40.6 \%$ women. Sixty-three per cent were CA, $28.5 \%$ were HA and $8.5 \%$ were NA. A total of 1542 patients (95\%) had at least one concomitant medical condition. Chest roentgenogram was abnormal in $97 \%$. Common organisms isolated overall were Haemophilus influenzae (from 204 patients), Staphylococcus aureas (from 152 patients), Streptococcus pneumoniae (from 143 patients ), Escherichia coli (from 113 patients) and $P$ seudomonas aeruginosa (from 111 patients). H influenzae and $S$ pneumoniae were most common in CA pneumonia, whereas $S$ aureus and Gram-negative organisms were more common in the HA group and Gram-negative agents in the NA group. One hundred and four patients developed complications. Fifteen per cent required intensive care unit admission. The average length of hospitalization in the CA and NA groups was 17 days and in the HA group, 43 days. At time of discharge 1261 patients $(78 \%)$ were cured or improved, and 361 patients (22\%) died during the admission.

ConcLusions: These results suggest that hospitalization for pneumonia in the 1990 s is primarily for elderly patients with significant co-morbidity. Although microbiology appears unchanged compared with earlier reports, the contemporary population is significantly sicker than previous cohorts. This may account for the persistently high morbidity and mortality despite better or newer antibiotics. (Pour le résumé, voir page 318)

Key Words: Community acquired pneumonia, Co-morbidity, Complications, Hospital acquired pneumonia, Nursing home acquired pneumonia, Outcome

Department of Medicine, The Wellesley Hospital and The Toronto Hospital, University of Toronto, Toronto, Ontario

Correspondence and reprints: Dr Charles K Chan, The Toronto Hospital, 200 Elizabeth Street, 10 EN-220, Toronto, Ontario M5G 2C4. Telephone 416-340-3235, fax 416-971-6427

Received for publication March 20, 1995. Accepted August 2, 1995 


\section{Pneumonie acquise dans la communauté, dans des établissements de soins prolongés et à l'hôpital : survol des caractéristiques cliniques, bactériologiques et radiologiques sur cinq ans}

But : Évaluer les caractéristiques cliniques, bactériologiques et radiographiques actuelles de patients hospitalisés souffrant de pneumonie acquise dans la communauté, dans un établissement de soins prolongés ou dans un hôpital, afin de déterminer l'évolution des patients.

Patients et Méthodes : Tous les dossiers hospitaliers de patients atteints de pneumonie au cours d'une période de cinq ans allant d'avril 1987 à mars 1992 ont été passés en revue de façon rétrospective. Les patients retenus pour l'étude sont tous ceux dont le diagnostic de pneumonie a été posé à partir des dossiers informatisés et des codes de diagnostic en vigueur au moment du congé. Les patients porteurs d'une pneumonie à Pneumocystis carinii ont été exclus. Des 74435 congés accordés au cours de la période de cinq ans, 1782 concernaient des patients qui répondaient aux critères d'inclusion.

RÉSULTATS : Les dossiers de 1622 cas sur ces 1782 ont été passés en revue. La moyenne d'âge était de 64,4 ans; $59,4 \%$ étaient des hommes et $40,6 \%$ des femmes. Chez soixante-trois pour cent, la pneumonie avait été acquise dans la communauté, chez $28,5 \%$, dans un établissement de soins prolongés et chez $8,5 \%$, dans un hôpital. En tout, 1542 patients $(95 \%)$ souffraient d'au moins un autre problème de santé. Les radiographies pulmonaires étaient anormales chez $98 \%$. Les organismes pathogènes isolés dans l'ensemble ont été Haemophilus influenzae (204 patients), Staphylococcus aureus (152 patients), Streptococcus pneumoniae (143 patients), Escherichia coli (113 patients) et Pseudomonas aeruginosa (111 patients). $H$. influenzae et $S$. pneumoniae ont été les plus fréquemment incriminés dans la pneumonie acquise dans la communauté, alors que $S$. aureus; les organismes pathogènes gram-négatifs étaient les plus courants dans le groupe souffrant de pneumonie acquise à l'hôpital et les organismes gram-négatifs, chez les patients des établissement de soins prolongés. Cent quatre patients ont présenté des complications. Quinze pour cent ont nécessité un séjour aux soins intensifs. La durée moyenne de l'hospitalisation pour le groupe atteint de pneumonie acquise dans la communauté et dans les établissement de santé a été de 17 jours et dans le groupe atteint de pneumonie acquise à l'hôpital, de 43 jours. Au moment du congé, 1261 patients (78\%) étaient guéris ou leur état s'était amélioré et 361 patients ( $22 \%$ ) sont décédés durant leur hospitalisation.

ConcLusions : Ces résultats suggèrent que l'hospitalisation pour pneumonie au cours des années 1990 s'observait principalement chez les patients âgés, atteints de comorbidité importante. Bien que la microbiologie semble inchangée en comparaison avec les rapports précédents, la population actuelle est nettement plus malade que les cohortes antérieures. Cela peut être dû à une morbidité et une mortalité qui restent en hausse malgré l'amélioration des nouveaux antibiotiques.

$\mathrm{T}$ HE FIRST REPORT OF A POPULATION SURVEY OF PNEUMONIA was by August Hirsch in 1881 (1), in which he described pneumonia to occur in epidemics and to be more prevalent in the elderly, the sick and those of low socioeconomic status. This report had followed the first successful culture of a bacterial organism from a patient with pneumonia by Louis Pasteur, who aptly named the organism Streptococcus pneumoniae. Hirsch's report appears to differ little from subsequent surveys of pneumonia. Morbidity and mortality in patients with pneumonia in the recent era remain high despite the development of effective antimicrobial agents and increasingly better understanding of the pathogenesis and etiology of pneumonia.

Accurate assessment of the overall burden of pneumonia on health care remains inaccurate since pneumonia is not a reportable illness and the majority of patients are managed in the ambulatory setting. However, statistical figures from the United States suggest that over 3.3 million cases of community acquired (CA) pneumonia occur annually (2). It is the fifth leading cause of death in those over 65 years of age (3). Although low in the out-patient setting, mortality is reported to be $25 \%$ in those requiring hospitalization. Highest mortality rates occur in the intensive care unit (ICU) setting (4-11), where it has been reported to be as high as $47 \%$ (12). Higher morbidity and mortality were observed in the elderly $(6,8,13)$ and in those with concurrent illnesses such as chronic ob- structive pulmonary disease (COPD), diabetes mellitus, chronic renal failure, congestive heart failure and chronic alcohol abuse (6,8-10). Paradoxically, increased longevity permits opportunity for development of medical illnesses and is likely responsible for the lack of significant improvement in the overall prognosis of pneumonia. In the past decade, there has been an increase in the pool of susceptible hosts, particularly patients with compromised immune defence systems. There has been a marked increase in human immunodeficiency virus (HIV) disease and in survivors of bone marrow and organ transplantation who are on chronic immunosuppressive agents. At the same time, the development of newer and more powerful antimicrobial agents has met with a parallel emergence of resistant and new strains of infecting organisms.

Recent publication of guidelines for the empiric management of CA pneumonia (14-17) underscores the importance of continually updating our knowledge of this persistent but ever-changing disease. The present study was undertaken to review the contemporary epidemiology of CA, nursing home (NA) and hospital acquired (HA) pneumonia in a community-based hospital. We sought to characterize the patient population at risk, the spectrum of clinical and roentgenographic presentation, the pattern of offending pathogens, the response to management and patient outcome.

We recently reported the results of an interim analysis of 
TABLE 1

Characteristics of 1622 patients admitted to hospital with pneumonia

\begin{tabular}{|c|c|c|c|}
\hline & Community acquired & Nursing home acquired & Hospital acquired \\
\hline Total number $(n=1622)$ & $1022(63 \%)$ & $138(8.5 \%)$ & $462(28.5 \%)$ \\
\hline Male $(n=964)$ & 609 & 82 & 273 \\
\hline Female $(n=658)$ & 413 & 56 & 189 \\
\hline \multicolumn{4}{|l|}{ Age (mean 64.4 years) } \\
\hline Male (years) & 61 & 78 & 62 \\
\hline Female (years) & 65 & 84 & 66 \\
\hline Average length of stay (days) & 16.3 & 17.4 & 42.9 \\
\hline Male & 15.3 & 18.7 & 46.0 \\
\hline Female & 17.7 & 15.5 & 38.5 \\
\hline Number of patients requiring oxygen at discharge & $27(3 \%)$ & $2(1.4 \%)$ & $10(2 \%)$ \\
\hline Number of patients requiring intensive care & $112(11 \%)$ & $4(3 \%)$ & $131(28 \%)$ \\
\hline Average length of ICU stay (days) & 7.1 & 5 & 9.5 \\
\hline Male (days) & 7.06 (65 patients) & 1.5 (2 patients) & 9.9 (76 patients) \\
\hline Female (days) & 7.15 (47 patients) & 8.5 (3 patients) & 8.9 (55 patients) \\
\hline Smoking history & $490(48 \%)$ & $26(18.5 \%)$ & $156(34 \%)$ \\
\hline Male & 325 & 18 & 113 \\
\hline Female & 165 & 8 & 43 \\
\hline Co-morbidity $\geq 2$ & $739(72 \%)$ & $97(70 \%)$ & $353(76 \%)$ \\
\hline Co-morbidity $=1$ & $226(22 \%)$ & $33(24 \%)$ & $94(20 \%)$ \\
\hline No co-morbidity & $57(6 \%)$ & $8(6 \%)$ & $15(3 \%)$ \\
\hline Complications & $50(4.9 \%)$ & $6(4.3 \%)$ & $48(10.4 \%)$ \\
\hline Death $(n=361 ; 22 \%)$ & $168(16 \%)$ & $34(25 \%)$ & $159(34 \%)$ \\
\hline
\end{tabular}

Co-morbidity was defined as chronic obstructive pulmonary disease, asthma, bronchiectasis, diabetes mellitus, chronic renal disease, congestive heart disease, underlying malignancy, immune deficiency (both primary and iatrogenic such as long term use of immunosuppressive agents) and chornic alcohol abuse; complications were defined as lung abscess, empyema, pleural effusion, congestive heart failure and pneumothorax. ICU Intensive care unit

the initial 1300 patients (18). The complete analysis of the final data set at 1622 patients is reported here.

\section{PATIENTS AND METHODS}

Study population: Patients were identified from a computer database of all discharges from the Wellesley Hospital in Toronto, Ontario during a five-year period from April 1987 to March 1992. All patients with a diagnosis of pneumonia encoded in the discharge diagnosis were included in the study. The Wellesley Hospital is a university-affiliated, 400-bed community hospital that functions mostly as a primary and secondary centre with annual total hospital discharge of 15,000 to 16,000. A small portion of discharges originates from a tertiary referral base due to proximity to The Princess Margaret Hospital/Ontario Cancer Institute, the major oncology referral hospital in southern Ontario and from the only burn unit in the city, located in the Wellesley Hospital. Patients with a diagnosis of Pneumocystis carinii pneumonia were excluded from the study. Those with HIV disease were not excluded.

Data collection: Information was manually extracted retrospectively from the hospital charts and recorded on a database sheet before final entry into a computer database program. Validity of data coding and entry was ensured by double entry. The following information was gathered: first, patient demographics such as age and sex; second, concurrent medical illnesses (defined as COPD, asthma, bronchiectasis, diabetes mellitus, chronic renal disease, congestive heart disease, underlying malignancy, immune deficiency [both pri- mary and iatrogenic such as long term use of immunosuppressive agents] and chronic alcohol abuse); past and current smoking history was recorded separately; third, laboratory findings including complete blood counts, serum sodium, chest roentgenogram (CXR) (in the majority of cases, the official radiology report was used although at times only the results of the clinical interpretation recorded on the chart were available; focal infiltrate was defined as infiltrate localized to one lobe; diffuse infiltrate was defined as involvement of two or more lobes) and microbiology results; fourth, clinical presentation including fever (temperature over $38^{\circ} \mathrm{C}$ ), chills, sweat, decreased level of consciousness, cough, sputum production and dyspnea; fifth, duration and type of antimicrobial agents used and presence of adverse drug reactions; sixth, development of complications (defined as lung abscess, empyema, pleural effusion, congestive heart failure and pneumothorax); seventh, need for oxygen therapy and ICU admission; eighth, length of stay in hospital and in ICU; ninth, final outcome (see section on outcome measurements).

The diagnosis of pneumonia was considered to be CA if the diagnosis was made within the first $72 \mathrm{~h}$ of admission, HA if made after $72 \mathrm{~h}$ and NA if the patient was a resident of a nursing home and the diagnosis was made within the first $72 \mathrm{~h}$.

Microbiological data: All microbiological data were extracted from the official Microbiology Department laboratory report form. Since these patients were not part of a prospective clinical study, investigations and work-ups for pneumonia were not standardized. Nevertheless, the diagnostic work-up reflect 
TABLE 2

Presence of co-morbid conditions in patients with pneumonia

\begin{tabular}{lccc}
\hline & $\begin{array}{c}\text { CA } \\
(\mathbf{n = 1 0 2 2})\end{array}$ & $\begin{array}{c}\text { NA } \\
(\mathbf{n = 1 3 8 )}\end{array}$ & $\begin{array}{c}\text { HA } \\
(\mathbf{n}=\mathbf{4 6 2})\end{array}$ \\
\hline Cardiac disease & 416 & 70 & 191 \\
Chronic alcoholism & 324 & 22 & 131 \\
COPD & 296 & 47 & 94 \\
Underlying malignancy & 143 & 14 & 124 \\
Chronic renal disease & 138 & 19 & 90 \\
Diabetes mellitus & 128 & 18 & 64 \\
Chronic steroid use & 128 & 18 & 71 \\
HIV infection & 76 & 1 & 8 \\
Asthma & 68 & 3 & 24 \\
Bronchiectasis & 26 & 1 & 1 \\
Leukemia & 23 & 0 & 22 \\
Lymphoma & 21 & 1 & 9 \\
Cystic fibrosis & 13 & 0 & 0 \\
Bone marrow transplant & 2 & 0 & 4 \\
recipient & & & \\
Other & 609 & 96 & 315 \\
\hline
\end{tabular}

${ }^{*}$ Excludes leukemia and lymphoma. CA Community acquired; COPD Chronic obstructive pulmonary disease; HA Hospital acquired; HIV Human immunodeficiency virus; NA Nursing home acquired

the standard clinical practice at the Wellesley Hospital for pneumonia and included sputum, if available, for Gram stain, culture and sensitivity; and blood for aerobic and anaerobic cultures. All specimens were processed through the Microbiology Department at the Wellesley Hospital. Blood cultures were grown in Bactec (Becton-Dickinson, Maryland) bottles and sputum samples were handled in the standard microbiological laboratory fashion. Tests for atypical agents such as Legionella species and mycobacteria, serum serology, thoracentesis, percutaneous needle aspiration and bronchoscopy with bronchoalveolar lavage (BAL) with or without protected brush were done only on selected patients, at the discretion of the attending and/or the consulting physicians. When ordered, testing for Legionella was by the direct fluorescent antibody method followed by culture. Mycobacteria was investigated initially with acid fast stain and fluorescent antibody stain followed by cultures at the Ontario Health Ministry's Mycobacterial Laboratories. If requested, acute and convalescent antibody titres for Mycoplasma pneumoniae were done.

All organisms isolated from blood, sputum and urine cultures within $72 \mathrm{~h}$ of diagnosis of pneumonia were recorded. Multiple isolates from a single patient were recorded as such in each patient file. However, these were treated as individual isolates in the final analysis.

Outcome measurements: Patients were considered to have improved or to be cured if the patient was alive and off antibiotics at the end of the hospitalization period. Those who discharged themselves against medical advice were included in the 'improved' group because it can be assumed that they were alive at the time of discharge. Death certificates of those who died during the hospital stay were reviewed. If the death certificate listed pneumonia as a cause of death, it was consid-
TABLE 3

Roentgenographic presentation of patients with pneumonia

\begin{tabular}{lccc}
\hline & $\begin{array}{c}\text { Community } \\
\text { acquired } \\
\text { (n=994) }\end{array}$ & $\begin{array}{c}\text { Nursing home } \\
\text { acquired } \\
\text { (n=132) }\end{array}$ & $\begin{array}{c}\text { Hospital } \\
\text { acquired } \\
\text { (n=442) }\end{array}$ \\
\hline Normal & $31(3 \%)$ & $3(3 \%)$ & $15(3 \%)$ \\
Focal & $684(69 \%)$ & $101(77 \%)$ & $301(68 \%)$ \\
Diffuse & $268(27 \%)$ & $27(20 \%)$ & $119(27 \%)$ \\
Pleural effusion & $35(4 \%)$ & $4(3 \%)$ & $29(7 \%)$ \\
Other & $1(0.1 \%)$ & 0 & 0 \\
\hline
\end{tabular}

Report of initial chest roentgenograms was available in 1568 patients. Focal infiltrate was defined as infiltrate localized to one lobe; diffuse infiltrate was defined as involvement of two or more lobes

TABLE 4

Presence of symptoms in patients with pneumonia

\begin{tabular}{lccc}
\hline Symptoms & $\begin{array}{c}\text { Community } \\
\text { acquired } \\
(\mathbf{n = 1 0 2 2})\end{array}$ & $\begin{array}{c}\text { Nursing home } \\
\text { acquired } \\
\text { (n=138) }\end{array}$ & $\begin{array}{c}\text { Hospital } \\
\text { acquired } \\
\text { (n=462) }\end{array}$ \\
\hline $\begin{array}{l}\text { Decreased level of } \\
\text { consciousness }\end{array}$ & 146 & 54 & 106 \\
Cough/sputum & 746 & 65 & 204 \\
Cough & 732 & 65 & 201 \\
Sputum & 560 & 44 & 126 \\
Fever & 537 & 69 & 243 \\
Chills & 291 & 10 & 36 \\
Sweats & 87 & 1 & 15 \\
Dyspnea & 312 & 74 & 218 \\
\hline
\end{tabular}

ered to be a pneumonia death. Need of oxygen therapy, ICU admission and development of complications of pneumonia as defined above were also recorded.

\section{RESULTS}

During the five-year period of the study (April 1987 through March 1992) 1782 of the 74,435 patients discharged (2.4\%) from the Wellesley Hospital had a diagnosis of pneumonia. Charts of 160 patients $(9 \%)$ were irretrievably lost. The remaining 1622 discharges available for review comprised the study population.

There were more men than women (964 cases or $59.4 \%$ versus 658 cases or $40.6 \%$, respectively). Mean age was 64.4 years (range 16 to 103 years). One thousand and twenty-two cases $(63 \%)$ were CA, $138(8.5 \%)$ were NA and $462(28.5 \%)$ were HA. These patients represented an ill population. One thousand five hundred and forty-two $(95 \%)$ had at least one concomitant medical condition. The majority (73\%) had two or more concurrent medical illnesses. The three groups were similar with respect to presence of co-morbidity. The NA group was older and had a lower incidence of a smoking history (Table 1). Common concomitant medical conditions were cardiac disease, chronic alcohol use, COPD and underlying malignancy (Table 2).

Initial CXR was reported on 1568 patients (97\%) and was abnormal in $97 \%$ of these, although a surprising $3 \%$ of pa- 
TABLE 5

Routine investigations in patients admitted to hospital with pneumonia

\begin{tabular}{lcccc}
\hline Analysis & $\begin{array}{c}\text { Community } \\
\text { acquired }(\mathbf{n = 1 0 2 2})\end{array}$ & $\begin{array}{c}\text { Nursing home } \\
\text { acquired (n=138) }\end{array}$ & $\begin{array}{c}\text { Hospital } \\
\text { acquired (n=462) }\end{array}$ & $\begin{array}{c}\text { Total } \\
(\mathbf{n}=1622)\end{array}$ \\
\hline $\begin{array}{l}\text { No cultures nor serology sent } \\
\begin{array}{l}\text { At least one specimen sent for microbiological stud- } \\
\text { ies (ie, sputum, blood, urine, }\end{array}\end{array}$ & $126(12 \%)$ & $36(26 \%)$ & $76(16 \%)$ & $238(15 \%)$ \\
$\begin{array}{l}\text { bronchoalveolar lavage and/or serology) } \\
\text { Both sputum and blood cultures }\end{array}$ & $896(88 \%)$ & $102(74 \%)$ & $386(84 \%)$ & $1384(85 \%)$ \\
\hline
\end{tabular}

TABLE 6

Number of patients with community acquired (CA), nursing home acquired (NA) and hospital acquired (HA) pneumonia in whom common pathogens were identified

\begin{tabular}{lcccc}
\hline & Total $(\mathbf{n = 1 6 2 2})$ & CA $(\mathbf{n = 1 0 2 2})$ & NA (n=138) & HA (n=462) \\
\hline Streptococcus pneumoniae & 143 & $114(12 \%)$ & $5(4 \%)$ & $24(5 \%)$ \\
Haemophilus influenzae & 204 & $134(13 \%)$ & $7(5 \%)$ & $63(14 \%)$ \\
Staphylococcus aureus & 152 & $77(8 \%)$ & $3(2 \%)$ & $72(16 \%)$ \\
Escherichia coli & 113 & $53(5 \%)$ & $12(9 \%)$ & $48(10 \%)$ \\
Pseudomonas aeruginosa & 111 & $55(5 \%)$ & $4(3 \%)$ & $52(11 \%)$ \\
Klebsiella pneumoniae & 76 & $38(4 \%)$ & $7(5 \%)$ & $31(7 \%)$ \\
Proteus mirabilis & 26 & $8(1 \%)$ & $2(1 \%)$ & $16(3 \%)$ \\
Viral agents & 15 & $13(1 \%)$ & 0 & $2(0.5 \%)$ \\
Moraxella catarrhalis & 12 & $8(1 \%)$ & 0 & $3(1 \%)$ \\
Legionella pneumoniae & 5 & $5(0.5 \%)$ & 0 & 0 \\
Mycobacteria & 5 & $5(0.5 \%)$ & 0 & 0 \\
\hline
\end{tabular}

Organisms identified on cultures of blood, sputum, bronchoalveolar lavage fluid, urine plus urine and serum serology. Patients who had the same organism isolated from multiple sites were counted only once

TABLE 7

Numbers of organisms recovered from different culture sites in 1622 patients with pneumonia

\begin{tabular}{|c|c|c|c|c|c|c|c|c|c|}
\hline & \multicolumn{3}{|c|}{ Blood } & \multicolumn{3}{|c|}{ Sputum } & \multicolumn{3}{|c|}{ Bronchoscopy } \\
\hline & CA & NA & HA & CA & NA & HA & CA & NA & HA \\
\hline Streptococcus pneumoniae & 39 & 1 & 4 & 81 & 4 & 20 & 4 & 0 & 0 \\
\hline Staphylococcus aureus & 9 & 0 & 15 & 60 & 3 & 53 & 12 & 0 & 11 \\
\hline Pseudomonas aeruginosa & 3 & 0 & 7 & 53 & 4 & 47 & 1 & 0 & 6 \\
\hline Klebsiella pneumoniae & 3 & 0 & 3 & 27 & 7 & 22 & 3 & 0 & 1 \\
\hline Moraxella catarrhalis & 0 & 0 & 0 & 8 & 1 & 3 & 0 & 0 & 0 \\
\hline Legionella pneumoniae & 0 & 0 & 0 & 2 & 0 & 0 & 3 & 0 & 0 \\
\hline Mycobacteria & 0 & 0 & 0 & 5 & 0 & 0 & 0 & 0 & 0 \\
\hline Viral agents & 1 & 0 & 0 & 0 & 0 & 0 & 6 & 0 & 1 \\
\hline Others & 35 & 0 & 42 & 66 & 7 & 29 & 25 & 0 & 8 \\
\hline
\end{tabular}

CA Community acquired; HA Hospital acquired; NA Nursing home acquired

tients were reported to have a normal CXR (Table 3). In the 54 patients for whom reports of the admission CXR could not be found, the data were treated as incomplete and were not included in the subsequent analysis. Focal radiographic abnormality was the most common finding in all three groups: $69 \%$ in CA, $77 \%$ in NA and $68 \%$ in $\mathrm{HA}$ (Table 3 ). There was no significant difference in the roentgenographic presentation in the three groups. Approximately three-quarters of the patients were documented to have cough and/or sputum production at the time of presentation. Fever and chills were reported in about half of the patients in each group (Table 4).
Few patients were started on antimicrobial therapy before hospital admission. Forty of 1022 patients in the CA group were documented to have been on antibiotics at the time of admission, eight in the NA group (6\%) and eight in the HA group (2\%).

In $85 \%$ of all patients, attempts were made to identify an infecting organism by means of cultures of sputum, blood, urine, BAL and/or serology (Table 5). Cultures of both blood and sputum were obtained in $79 \%$ of patients. Investigations were performed more often in the CA group. Summary of all 
TABLE 8

Number of organisms recovered from serum and urine serology and urine culture in patients with pneumonia

\begin{tabular}{lcccccc}
\hline & \multicolumn{3}{c}{ Serology } & \multicolumn{3}{c}{ Urine } \\
& CA & NA & HA & CA & NA & HA \\
\hline Streptococcus pneumoniae & 0 & 0 & 0 & 0 & 0 & 0 \\
Haemophilus influenzae & 0 & 0 & 0 & 8 & 3 & 12 \\
Staphylococcus aureus & 0 & 0 & 0 & 4 & 0 & 8 \\
Pseudomonas aeruginosa & 0 & 0 & 0 & 0 & 0 & 0 \\
Klebsiella pneumoniae & 0 & 0 & 0 & 9 & 1 & 8 \\
Escherichia coli & 0 & 0 & 0 & 32 & 5 & 28 \\
Proteus mirabilis & 0 & 0 & 0 & 6 & 2 & 6 \\
Moraxella catarrhalis & 0 & 0 & 0 & 0 & 0 & 0 \\
Legionella pneumoniae & 2 & 0 & 0 & 1 & 0 & 0 \\
Mycobacteria & 5 & 0 & 0 & 0 & 0 & 0 \\
Viral agents & 7 & 0 & 2 & 0 & 0 & 0 \\
\hline
\end{tabular}

CA Community acquired; HA Hospital acquired; NA Nursing home acquired

cultures (blood, sputum, BAL fluid, urine) plus urine and serum serology found the highest yield from sputum cultures. Yield of a positive result from sputum and/or blood culture in the overall group was $53 \%$. Only $6 \%$ of patients had positive blood cultures. A summary of all investigations done to identify the offending pathogen is presented in Tables 6,7 and 8 . Overall, the predominant organisms found from all investigations were Haemophilus influenzae (isolated from 204 patients), Staphylococcus aureus (from 152 patients) and $S$ pneumoniae (from 143 patients). The pattern of organisms detected differed in the three groups. In the CA group, $H$ influenzae, $S$ pneumoniae and $S$ aureus were the most common organisms. In the HA group, $S$ aureus and Gram-negative organisms predominated. In the NA group, 22 of the 32 Gramnegative organisms isolated were from either blood (two) or sputum (20) (Tables 6,7). The main organisms documented from blood cultures were $S$ pneumoniae and $S$ aureus (Table 7). Yield of investigation of bronchoscopy specimens and serum and/or urine serology in the identification of the infecting organism was low.

Two hundred and forty-seven patients (15\%) were admitted to ICU. The highest ICU admission rate, not surprisingly, was in the HA group (28\%) and the lowest in the NA group (3\%). The average length of ICU stay was 7.1, 5 and 9.5 days in the CA, NA and HA groups, respectively. Those admitted to ICU were similar to the overall group in terms of presence of co-morbid illnesses (Table 1).

Only 39 patients $(2.4 \%)$ required home oxygen therapy at the time of discharge although, not surprisingly, more patients required oxygen therapy during their course in hospital. One hundred and four patients $(6.4 \%)$ developed complications of pneumonia, most commonly in the HA group. The most common complication was the development of pleural effusion.

The average length of stay for the entire group was 24 days. Shorter hospitalization courses of 16.3 and 17.4 days were seen in the CA and NA groups, respectively. The average hospitalization in the HA group was 42.9 days (Table 1).

In all, 1261 patients $(78 \%)$ were deemed to have improved
TABLE 9

Cause of mortality in patients hospitalized with pneumonia

\begin{tabular}{lccc}
\hline & $\begin{array}{c}\text { CA } \\
(\mathbf{n = 1 0 2 2})\end{array}$ & $\begin{array}{c}\text { NA } \\
(\mathbf{n = 1 3 8 )}\end{array}$ & $\begin{array}{c}\text { HA } \\
(\mathbf{n = 4 6 2 )}\end{array}$ \\
\hline Improved or cured & $864(84 \%)$ & $104(75 \%)$ & $303(66 \%)$ \\
Dead & $168(16 \%)$ & $34(25 \%)$ & $159(34 \%)$ \\
$\begin{array}{l}\text { Pneumonia a } \\
\text { contributing cause of } \\
\text { death }\end{array}$ & $75(7 \%)$ & $10(7 \%)$ & $70(15 \%)$ \\
$\begin{array}{l}\text { Pneumonia not a } \\
\text { contributing cause of } \\
\text { death }\end{array}$ & $74(7 \%)$ & $20(15 \%)$ & $71(15 \%)$ \\
$\begin{array}{l}\text { Cause of death not } \\
\text { assessed }\end{array}$ & $19(2 \%)$ & $4(3 \%)$ & $18(4 \%)$ \\
\hline CA Community acquired; HA Hospital acquired; NA Nursing home acquired
\end{tabular}

or to be cured at the time of discharge. Three hundred and sixty-one patients (22\%) died during admission to hospital. The highest mortality rate was in the HA group (34\%) and the lowest in the CA group (16\%) (Table 1). Mortality in the NA group was $25 \%$. Death certificates were reviewed in 320 cases $(89 \%)$. Pneumonia was listed as a contributing cause of death in 165 of the 320 deaths (52\%). Seventy-five of 149 deaths in the CA group, 10 of 30 in the NA group and 70 of 141 in the HA group were attributed to pneumonia (Table 9).

\section{DISCUSSION}

Our five-year review of all patients discharged from hospital with a diagnosis of pneumonia during the period from April 1987 to March 1992 describes the most contemporary population of in-patients with pneumonia, and is two to three times larger than the most recently published reports $(5,6)$. Data from these 1622 cases of pneumonia continue to support previous observations that pneumonia in the 1990s remains a serious illness with significant morbidity and mortality. Pneumonia accounted for $2.6 \%$ of all discharges from our hospital during this period.

Although it appears that few patients were started on outpatient antimicrobial therapy, the high incidence of co-morbid illness, with $95 \%$ having at least one concomitant illness and $73 \%$ having two or more, suggests that, as a group, these elderly patients are indeed ill. These contemporary hospitalized patients are, in fact, a sicker population than previous cohorts. Previous studies $(4,5,7,9-11)$ reported a lower incidence of comorbid illness in patients hospitalized with pneumonia. In the Fang et al (5) study population of 359 patients with hospitalized CA pneumonia $30.6 \%$ had no underlying medical disease, and in the 719 patients studied by Marrie et al (6) $13 \%$ had no concurrent medical illness. The age, sex distribution and length of hospitalization of previous cohorts were comparable with ours (Table 10).

The incidence of HA pneumonia in our patient population was 6 in 1000. This is comparable with previous reports from Canada and the United States $(19,20)$.

Previous studies have reported $S$ pneumoniae to be the 
predominant organisms in all groups with pneumonia $(4-11,13,21,22)$. In the community setting, $H$ influenzae and $S$ aureus have been found to be important pathogens as well. In our study, $H$ influenzae was the most common organism isolated overall. However, pathogenicity cannot be verified because the majority of the isolates were from sputum rather than blood cultures. Among organisms recovered from blood cultures, $S$ pneumoniae remains the predominant pathogen. Legionella pneumoniae is an uncommon cause of pneumonia in our population in contrast to previous reports $(4-6,9,10,23)$. This is likely a reflection of regional differences in the prevalence of Legionella infections.

Although a higher incidence of Gram-negative organisms was found in NA and HA pneumonia, $S$ aureus remained a significant pathogen, particularly in the HA group. These findings are consistent with other reports of nosocomial pneumonia (24-32).

The pattern of occurrence of organisms for the three types of pneumonia (Table 6) concur with those outlined in the recent guidelines on the initial management of pneumonia, and further support their recommendations of empiric antimicrobial therapy $(14,15,17)$.

In $26 \%$ of the NA group, there was no attempt to document a pathogen (Table 5). This may represent a more pragmatic and less invasive therapeutic approach to this subpopulation. It is, however, surprising that $12 \%$ in the CA group and $16 \%$ of HA group did not have any cultures or serology done. The reasons for this are not clear.

As with previous studies (5), CXR appearance and the presence of specific presenting signs and symptoms such as cough, sputum and decreased level of consciousness were nonspecific and were not associated with any particular etiologic agent.

The complication rate in our study was low. However, we confined our definition of complications (see Patients and Methods Section) to those that could be confidently attributable to pneumonia. Other complications such as renal failure or pulmonary complications cannot be attributed solely to pneumonia in a population with high co-morbid illness, particularly in a retrospective context.

Overall mortality in the present study was $22 \%$, with the highest mortality rate seen in the HA group and the lowest in the CA group, where it was $16 \%$. Overall mortality in CA pneumonia in the 719 patients described by Marrie et al (6) and in the 359 patients described by Fang et al (5) was $21 \%$ and $13.7 \%$, respectively (Table 9 ). Therefore, despite being a sicker population with more concomitant illnesses, the overall mortality is comparable with that of previous groups $(4-11,22,23)$. In review of the death certificates of 320 of the 361 deaths in our series, pneumonia was found to be a contributing cause of death in 165 cases. Specific cause of death was not reported in either of the two groups described by Marrie et al (6) and Fang et al (5). We could not confidently report any deaths as a direct result from pneumonia since guidelines for completing death certificates are not strict and open to interpretation. Moreover, the death certificates in our patients were completed by various physicians. Thus, pneumonia
TABLE 10

Recent studies of pneumonia

\begin{tabular}{lccc}
\hline & $\begin{array}{c}\text { Present } \\
\text { study 1995 }\end{array}$ & $\begin{array}{c}\text { Marrie et al } \\
\mathbf{1 9 8 9}(\mathbf{6})\end{array}$ & $\begin{array}{c}\text { Fang et al } \\
\mathbf{1 9 9 0 ( 5 )}\end{array}$ \\
\hline $\begin{array}{l}\text { Study period } \\
\begin{array}{l}\text { Number of } \\
\text { patients }\end{array}\end{array}$ & $1987-1992$ & $1981-1987$ & $1986-1987$ \\
$\begin{array}{l}\text { Study design } \\
\text { Mean age (years) }\end{array}$ & Retro & 719 & 359 \\
$\begin{array}{l}\text { Length of stay } \\
\text { (days) }\end{array}$ & 64.4 & 60 & Pro \\
Mortality & $24.0^{*}(16.3)$ & 17.6 & 62 \\
$\geq 1$ Co-morbidity & $95 \%$ & $87 \%$ & $?$ \\
\hline
\end{tabular}

*The results are for the entire study group. Numbers in parentheses are the results in the community acquired group. Cases studied by Fang et al and Marrie et al were community acquired pneumonia. Pro Prospective; Retro Retrospective

listed on the death certificate as the cause or as a contributing cause of death was treated in the same manner for the purpose of this study.

Studies have shown that patients with pneumonia and concurrent illness have more severe disease $(9,10)$. The high incidence of co-morbidity in our patient population is likely a reflection of the current admission criteria for pneumonia that admit primarily sick, elderly patients with severe disease. The current trend to manage more patients in the out-patient setting for economic reasons may have in fact adversely biased the mortality outcome of a study based on an in-patient population.

We recognize limitations to the interpretation of the data due to the retrospective nature of this study. The definition of pneumonia was based on available clinical and laboratory data and the diagnosis was made by the attending or consulting physicians. However, in studies comparing the accepted diagnostic criteria for pneumonia with the gold standard (a pathological assessment of pulmonary tissue), these criteria were found to be neither specific nor infallible $(26,33)$. The strength of the study is the generalizability of the results to other community-based hospitals in North America. Although complete and definitive data are not available in the work-up and management of pneumonia, the information available mirrors what clinicians have to rely on in general practice.

Although our yield from blood and sputum cultures is comparable with previous reports, pathogenicity of organisms recovered from sputum or BAL fluid cannot be ascertained. The microbiological results of this study may be over-implicating some organisms while under-representing others, particularly those that required special tests for detection (eg, viral agents that are detected on acute and convalescent titres). This is particularly true in cases where the putative organism(s) were isolated from sputum cultures. The retrospective nature of the study did not allow us to accept or refute the results based on the clinical context or on the quality of the sputum examined. Therefore, we chose to record all isolates obtained. However, differentiating a colonizer from a pathogen in cultures of respiratory secretions is a common clinical problem and one that is 
not readily correctable without invasive procedures and even in the most stringent prospective studies.

\section{CONCLUSIONS}

Our large scale study on a contemporary series of patients hospitalized for pneumonia suggests that the spectrum of microorganisms implicated in pneumonia in the 1990s is similar to that of the previous decades. However, the types of patients being hospitalized for pneumonia have changed to include primarily elderly patients with multiple co-morbidity. Hence, despite significant advances in the development of diagnostic tests and antimicrobials, the overall mortality rate for the current population remains high.

ACKNOWLEDGEMENTS: The authors thank the staff at the Health Records Department of the Wellesley Hospital for their cooperation and assistance in locating over 1600 charts. This work was supported in part by a grant from Roche Canada Ltd.

\section{REFERENCES}

1. Brockbank EM, Brockbank W. In: Bett WR, ed. The History and Conquest of Common Diseases. Norman: University of Oklahoma Press, 1954:84-98.

2. Garibaldi RA. Epidemiology of community acquired respiratory tract infections in adults. Am J Med 1985;78(Suppl 6B):32-7.

3. Hospitalizations for the leading causes of death among the elderly - United States, 1987. MMWR 1990;39:777-85.

4. Bates JH, Campbell D, Barron AL, et al. Microbial etiology of acute pneumonia in hospitalized patients. Chest 1992;101:1005-12.

5. Fang G-D, Fine M, Orloff J, et al. New and emerging etiologies for community acquired pneumonia with implications for therapy. Medicine 1990;69:307-16.

6. Marrie TJ, Durant H, Yates L. Community acquired pneumonia requiring hospitalization: a 5-year prospective study. Rev Infect Dis 1989;11:586-99.

7. Woodhead MA, Macfarlane JT. Prospective study of etiology and outcome of pneumonia in the community. Lancet 1987;i:671-4.

8. Ortqvist A, Sterner G, Nisson JA. Severe community acquired pneumonia: factors influencing need of intensive care treatment and prognosis. Scand J Infect Dis 1985; 17:377-86.

9. Torres A, Serra-Batlles J, Ferrer A, et al. Severe community acquired pneumonia: epidemiology and prognostic factors. Am Rev Respir Dis 1991;144:312-8.

10. Pachon J, Prados MD, Capote F, Cuello JA, Garnacho J, Verano A. Severe community acquired pneumonia: etiology, prognosis and treatment. Am Rev Respir Dis 1990;142:369-73.

11. Venkatesan P, Gladman J, Macfarlane JT, et al. A hospital study of community acquired pneumonia in the elderly. Thorax 1990;45:254-8.

12. Sorensen J, Cederholm I, Carlsson C. Pneumonia: a deadly disease despite intensive care treatment. Scand J Infect Dis 1986;18:329-35.

13. Woodhead MA, Macfarlane JT, Rodgers FG, Laverick A, Pilkington R, Macrae AD. Aetiology and outcome of severe community acquired pneumonia. J Infect 1985;10:204-10.

14. American Thoracic Society. Guidelines for the initial management of adults with community acquired pneumonia: diagnosis, assessment of severity and initial antimicrobial therapy. Am Rev Respir Dis 1993;148:1418-26.
15. Mandell LA, Niederman M, The Canadian Community Acquired Pneumonia Consensus Group. Antimicrobial treatment of community acquired pneumonia in adults: a conference report. Can J Infect Dis 1993;4:25-8.

16. Rodnick JE, Gude JK. Diagnosis and antibiotic treatment of community acquired pneumonia. West J Med 1991;154:405-9.

17. The Canadian Hospital Acquired Pneumonia Consensus Conference Group. The initial antimicrobial treatment of hospital acquired pneumonia in adults: a conference report. Can Respir J 1994;1:110-4.

18. Chow CW, Senathiragah N, Rawji M, Chan M, Lee-Pack LR, Chan CK. Interim report on drug utilization review of community acquired, nursing home acquired and nosocomial pneumonia: clinical, bacteriological and radiological spectrum. Can J Infect Dis 1994;5(Suppl C):

20C-7C.

19. Louie M, Dyck B, Parker S, Sekla L, Nicolle LE. Nosocomial pneumonia in a Canadian tertiary care centre: a prospective surveillance study. Infect Control Hosp Epidemiol 1991;12:356-63.

20. Dal Nogare AR. Nosocomial pneumonia in the medical and surgical patient. Med Clin North Am 1994;78:1081-90.

21. Felman $\mathrm{C}$, Kallenbach JM, Levy $\mathrm{H}$, et al. Community acquired pneumonia of diverse aetiology: prognostic features in patients admitted to an intensive care unit and a 'severity of illness' score. Intensive Care Med 1989;15:302-7.

21. Ostergaard L, Anderson PL. Etiology of community acquired pneumonia: evaluation by transtracheal aspiration, blood culture or serology. Chest 1993;104:1400-7.

22. Rello J, Quintana E, Ausina V, Net A, Prats G. A three year study of severe community acquired pneumonia with emphasis on outcome. Chest 1993;103:232-5.

23. Rello J, Quintana E, Ausina V, et al. Incidence, etiology and outcome of pneumonia in mechanically ventilated patients. Chest 1991;100:439-44.

24. Jimenez P, Torres A, Rodriguez-Roisin R, et al. Incidence and etiology of pneumonia acquired during mechanical ventilation. Crit Care Med 1989;17:882-5.

26. Potgieter PD, Hammond JMJ. Etiology and diagnosis of pneumonia requiring ICU admission. Chest 1992;101:199-203.

27. Rodriguez de Castro F, Violan JS, Capuz BL, Luna JC, Rodriguez BG, Alonso JLM. Reliability of the bronchoscopic protected catheter brush in the diagnosis of pneumonia in mechanically ventilated patients. Crit Care Med 1991;19:171-5.

28. Ruis-Santana S, Jimenez AG, Esteban A, et al. ICU pneumonias: a multi-institutional study. Crit Care Med 1987;15:930-2.

29. Fagon J-Y, Chastre J, Domart $Y$, et al. Nosocomial pneumonia in patients receiving continuous mechanical ventilation. Am Rev Respir Dis 1989;139:877-84.

30. Pham LH, Brun-Buisson C, Legrand $P$, et al. Diagnosis of nosocomial pneumonia in mechanically ventilated patients. Am Rev Respir Dis 1991;143:1055-61.

31. Chastre J. Prospective evaluation of the protected specimen brush for the diagnosis of pulmonary infections in ventilated patients. Am Rev Respir Dis 1984;130:924-9.

32. Fagon J-Y, Chastre J, Hance AJ, et al. Detection of nosocomial lung infection in ventilated patients: use of a protected specimen brush and quantitative culture techniques in 147 patients. Am Rev Respir Dis 1988;138:110-6.

33. The British Thoracic Society Research Committee and The Public Health Laboratory Service. The aetiology, management and outcome of severe community acquired pneumonia on the intensive care unit. Respir Med 1992;86:7-13. 


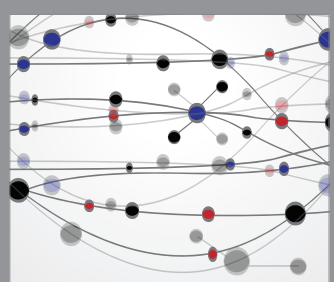

The Scientific World Journal
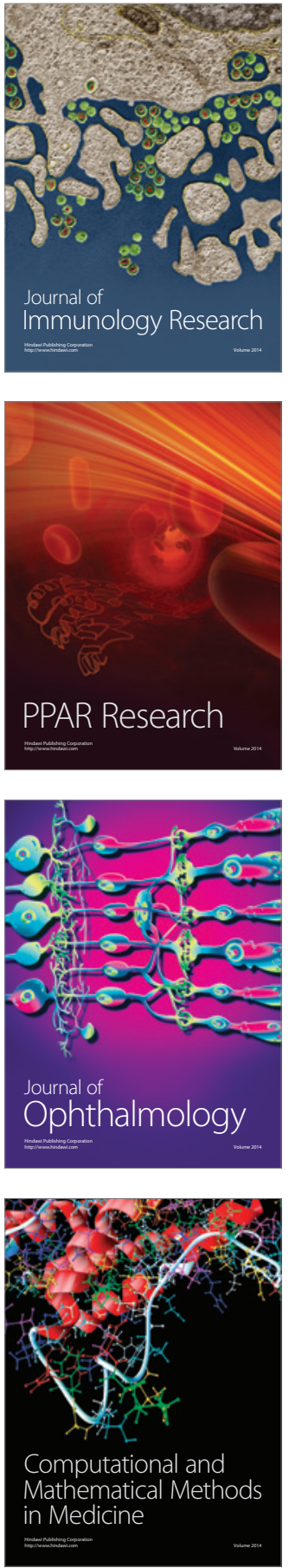

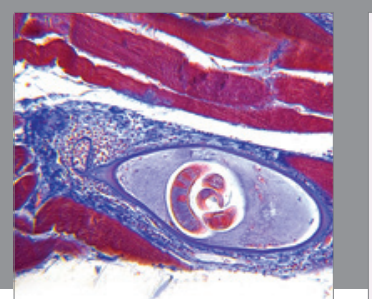

Gastroenterology Research and Practice

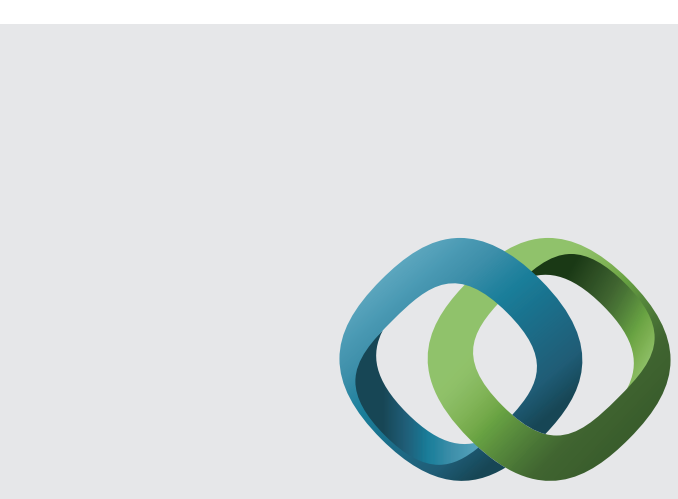

\section{Hindawi}

Submit your manuscripts at

http://www.hindawi.com
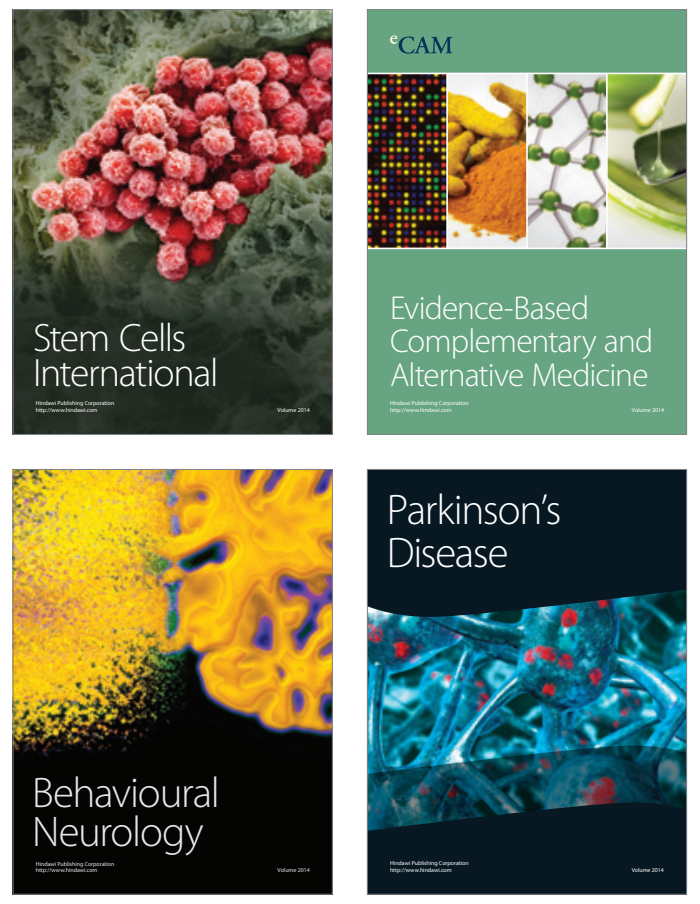
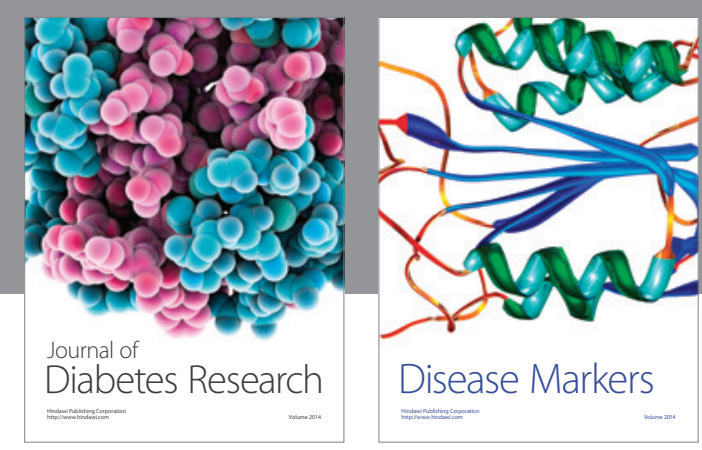

Disease Markers
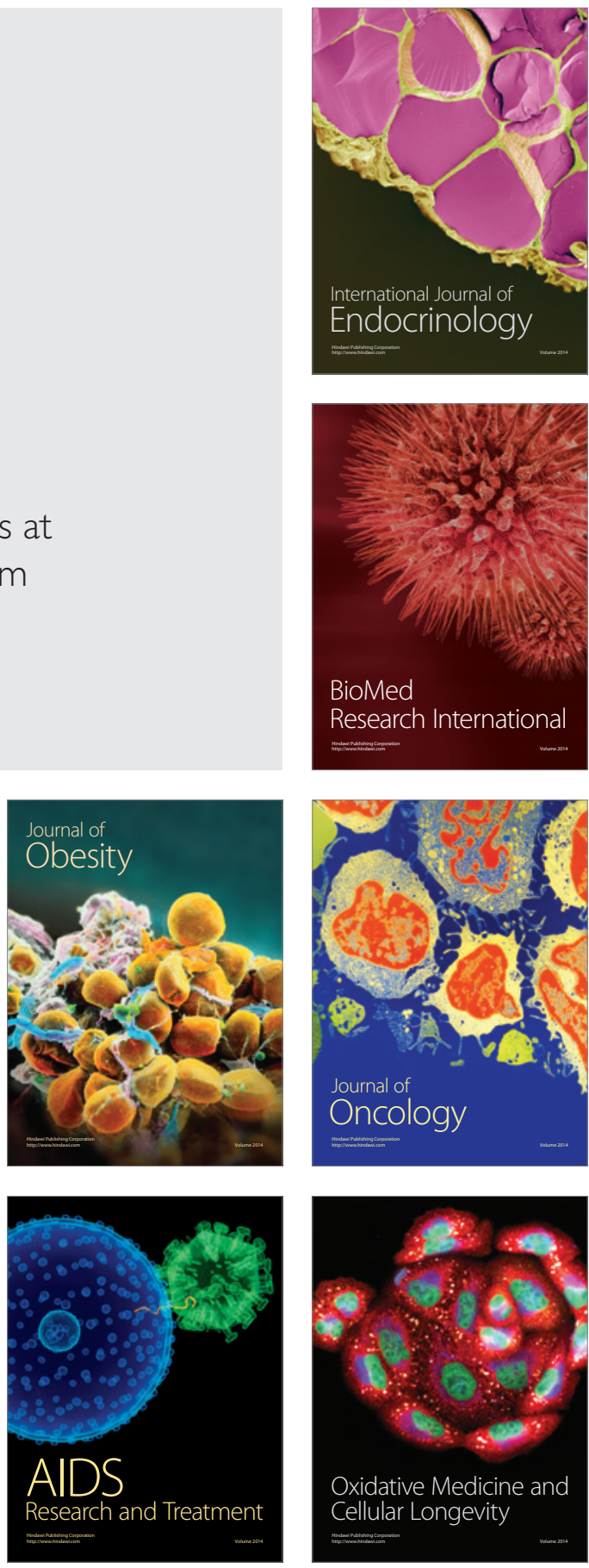